\title{
Compersion: When Jealousy-inducing Situations Don't (Just) Induce Jealousy
}

\author{
Rhonda N. Balzarini ${ }^{1}$, James N. McDonald ${ }^{2}$, Taylor Kohut ${ }^{3}$, Justin J. Lehmiller ${ }^{4}$, Bjarne M. \\ Holmes $^{5}$, \& Jennifer J. Harman ${ }^{2}$ \\ ${ }^{1}$ Department of Psychology, Texas State University, San Marcos, TX \\ ${ }^{2}$ Department of Psychology, Colorado State University, Fort Collins, CO \\ ${ }^{3}$ Department of Psychology, University of Western Ontario, London, ON \\ ${ }^{4}$ The Kinsey Institute, Indiana University, Bloomington, IN \\ ${ }^{5}$ Department of Psychology, Champlain College, Burlington, VT
}

This is the accepted, pre-publication version of the article, which appears in:

Balzarini, R. N., McDonald, J. N., Kohut, T., Lehmiller, J. J., Holmes, B. M., \& Harman, J. (2020). Compersion: When Jealousy-inducing Situations Don’t (Just) Induce Jealousy. Archives of Sexual Behavior, in press.

This work has been supported by an Ontario Trillium Award and Mitacs Accelerate Grant awarded to Rhonda Balzarini.

Correspondence concerning this article should be addressed to Rhonda Balzarini, Department of Psychology, Texas State University, San Marcos, TX 78666. E-mail: rnb85@txstate.edu or balzarinir@gmail.com. 


\begin{abstract}
Emotional reactions to a partner's extradyadic romantic interests are assumed to be negative and characterized by jealousy, an emotional state that arises over a perceived threat to one's relationship. Yet, reactions may also be positive, and involve compersion, or taking joy in one's partner's pleasure in other sexual and relational encounters. Although some have argued that compersion is the opposite of jealousy, research has shown that compersion and jealousy are not opposing constructs, despite being treated this way in both theoretical and empirical research. Using a convenience sample of polyamorous $(N=3,530)$ and monogamous $(N=1,358)$ individuals we draw on theories of jealousy, emotional ambivalence, and emotional forecasting to examine people's anticipated affective responses to hypothetical situations involving a partner's extradyadic relations, and assess whether experience with having a partner engage in extradyadic relations was associated with anticipating less jealousy and more compersion. Results suggest that people in polyamorous relationships report less jealousy and more compersion with their partners, and that personal experience involving a partner's extradyadic romantic interests predicted more compersion and less jealousy, with experience predicting greater increases in compersion among monogamous than polyamorous participants. Finally, while anticipated compersion was associated with greater relationship satisfaction, neither jealousy nor ambivalence were associated with relationship satisfaction. These results further demonstrate that individuals can experience both positive and negative reactions to a partner's extradyadic relations, both based on actual experience and projection of responses to future events, and that real-life experiences are important in anticipating these emotions.
\end{abstract}

Keywords: compersion; jealousy; consensual nonmonogamy; polyamory; monogamy; affective forecasting 


\section{Compersion: When Jealousy-inducing Situations Don't (Just) Induce Jealousy}

\section{Introduction}

Scholars have recently posited that the family system and the rules regarding romantic relationships are altering (Lebowitz, 2017), with a substantial number of people from diverse backgrounds interested in, or engaging in, polyamorous relationships (Balzarini, Dharma, Kohut, Campbell, Lehmiller, et al., 2018; Levine, Herbenick, Martinez, Fu, \& Dodge, 2018; Haupert et al., 2017) — relationships that permit loving more than one person — and other forms of consensually non-monogamous relationships (Moors, 2016; Rubin, Moors, Matsick, Ziegler, \& Conley, 2014). Despite increased interest in relationships that extend beyond the monogamous dyad, monogamy is a firmly entrenched norm within Western culture and is perceived to be ubiquitous and superior to other relationship orientations (Bittman \& Pixley, 1997; Conley, Moors, Matsick, \& Ziegler, 2013; Henrich, Boyd, \& Richardson, 2012; Ryan \& Jetha, 2010; Stacey, 1996). Many people hold the view that relationships with multiple romantic partners are less passionate, close, and trusting (Conley et al., 2013), and that having concurrent romantic relationships undermines satisfaction and commitment within each relationship (Wolfe, 2003). Indeed, lay perceptions of consensually non-monogamous relationships assume that individuals in polyamorous relationships must feel threatened and jealous by their partners having their sexual and relational needs met by other intimate partners (Mint, 2004). The premise that a person would consent to their partner's extradyadic sexual and romantic activities runs contrary to a general assumption underlying many theories in social and relationship psychology which project that, if one truly loves their partner, such activities must incite jealousy, or negative emotional reactions (e.g., Conley, Matsick, Moors, \& Ziegler, 2017). Yet, past work has shown that people in polyamorous relationships report relatively high levels of relationship quality, low 
levels of jealousy (Conley et al., 2017; Visser \& McDonald, 2007; Mitchell et al., 2014; Ritchie \& Barker, 2006), and, in some instances, actually report experiencing positive emotions in response to a partner's extradyadic relations (Aumer et al., 2014; Deri, 2015; Mogilski et al., 2019). That is, although people in polyamorous relationships do at times experience jealousy (Deri, 2015; Visser \& McDonald, 2007), they also report experiencing compersion, or positive, joyous feelings in response to a partner interacting romantically or sexually with someone else (Ritchie \& Barker, 2006).

In the current study we sought to assess whether people in polyamorous relationships experience more positive emotions, stemming from experiences of compersion, and fewer negative emotions, stemming from experiences of jealousy, in response to partner's extradyadic involvement compared to people in monogamous relationships. However, because people can experience both positive and negative reactions in response to a partner's extradyadic interests, we also sought to extend this work and assess the effects of experiencing ambivalent emotions (e.g., positive and negative feelings) towards a partner's extradyadic involvement, and whether experiencing ambivalent emotions is associated with relationship quality. Lastly, we sought to understand why people in polyamorous relationships are more apt to report positive responses, or compersion, and whether anticipated positive and negative reactions were associated with actual experiences and forecasted emotions in response to a partner's extradyadic involvement based on past experiences.

\section{Emotional Ambivalence}

Barrett and Bliss-Moreau's (2009) circumplex model organizes emotional episodes like degree marks on a compass - the core affective states of "pleasant" and "unpleasant" are as mutually exclusive as traveling east and west. The circumplex model assumes that emotions of 
opposite valence (positive and negative emotions) are mutually exclusive experiences, neutralizing each other in the same way that an acid counteracts a base (Larsen \& McGraw, 2014). However, emotions may be more complex, with some people reporting emotional experiences that are simultaneously positive and negative (e.g., An et al., 2017). In fact, a growing line of research (e.g., Larsen \& Green, 2013; Larsen \& McGraw, 2011; Larsen, McGraw, \& Cacioppo, 2001) has demonstrated that "bittersweet" experiences, particularly in regard to interpersonal relationships, can evoke "mixed emotions," which are blended emotions where a person experiences opposite valence emotions concurrently (Larsen \& McGraw, 2014). For example, mothers can experience positive feelings towards the boundaries established by their toddlers' growing independence, but simultaneously experience feelings of anxiety and loss created by those same boundaries (Dunbar, 2008). Similarly, people report experiencing emotional ambivalence in their romantic relationships. For example, people who are considering ending a relationship may simultaneously think about the possible ramifications of staying in the relationship or leaving it (Joel, MacDonald, \& Page-Gould, 2018), weighing both approach (i.e., desirable things which might be acquired) and avoidance motivations (i.e., undesirable things which would be eliminated from one's life) for each alternative. In questioning whether to stay or to go in a relationship, many individuals do not simply lean one way or the other, but rather experience ambivalence, which results in, "conflicting pressures on relationship quality and stability" (p. 8). Indeed, there is a growing body of research that shows the ubiquity of ambivalence - or the simultaneous experience of positive and negative emotional reactions toward a person or situation (Rothman, Pratt, Rees, \& Vogus, 2016).

\section{Emotional Ambivalence in Response to Extradyadic Relations}


One domain in which internal conflict and ambivalence may be particularly salient concerns a relationship partner's activities outside of the relationship. When an individual dedicates attention to things outside of their romantic relationship (e.g., family, friends, a career), their partner may be happy to see them enjoying outside activities, while also perceiving those diversions as threats to their relationship (e.g., alternatives to the relationship; Rusbult, 1983). This seems especially likely to be the case for extradyadic romantic relationships which may pose a threat to the existing relationship above and beyond other activities a partner can engage in (e.g., catching a movie with a friend). For example, research has shown that when people imagine (Harris, 2000; 2003; Thompson, Zimmerman, Kulibert, \& Moore, 2017) or discover (Edlund, Heider, Scherer, Farc, \& Sagarin, 2006; Kuhle, 2011) a partner's extradyadic romantic involvement they often engage in behaviors like mate guarding (Buss, 2002; Buss, Shackelford, \& McKibbin, 2008), and report negative emotional experiences like jealousy (AlShawaf, Conroy-Beam, Asao, \& Buss, 2016; Buss 2000 for a review of research), which may help to prevent the potential loss of a romantic partner.

Research has shown that perceiving a threat to one's relationship can elicit cognitive, behavioral, and emotional reactions which constitute romantic jealousy (Chung \& Harris, 2018; Elphinston, Feeney, \& Noller, 2011; Harris \& Darby, 2010; Parrott, 1991; Parrott \& Smith, 1993; White \& Mullen, 1989), with perceptions of relationship threat enhancing experiences of jealousy (Rydell, McConnell, \& Bringle, 2004). According to Pfeiffer and Wong (1989), although the experience of jealousy can combine multiple emotions, and although individuals vary in the combination of emotions they experience when they perceive a relationship threat, "any emotional reaction" to a perceived relationship threat "can be labelled a jealous reaction" (p. 182). Although researchers generally perceive jealousy as "a combination of negative 
emotions" (Pfeiffer \& Wong, 1989, p. 182), Pfeiffer and Wong recognize the potential for a positive reaction to such a situation. However, given the scaling of commonly used measures of jealousy—which assume that positive and negative valence emotions are mutually exclusivethis recognition only seems to matter insofar as a positive reaction represents an absence of a negative reaction. From the perspective of ambivalence, this view may not adequately represent the complexity of people's reactions to partner's extradyadic sexual and romantic interactions. For some individuals, the positive emotional reactions traditionally dismissed by researchers may play an important role in their relationships, and those emotions may not be mutually exclusive of negative emotions.

The term compersion has long been used by polyamorous individuals to describe positive or joyous feelings in response to a partner interacting romantically or sexually with someone else (Wolfe, 2003). While some researchers have described compersion as the opposite of jealousy (Anapol, 1998), there is no empirical evidence that that is an accurate description (see Aumer et al., 2014; Mogilski et al, 2019). Indeed, other researchers have described compersion in terms independent of jealousy, as the feeling of joy one feels knowing that their partners are sharing joy and love with others (Ritchie \& Barker, 2006), and suggest that individuals may experience compersion as an emotion, like the happiness one generally feels when their partner receives recognition at work, or accomplishes something important to them (Sheff, 2013). Research on compersion has been sparse so far but suggests that people in polyamorous relationships (compared to those in monogamous relationships) experience higher levels of compersion and lower levels of jealousy (Mogilski et al., 2019), and although individuals in polyamorous relationships do still report jealousy (Deri, 2015; Kohut, Balzarini, Lehmiller, Harman, \& Holmes, 2016; Visser \& McDonald, 2007), they report being able to navigate and manage their 
jealousy through communicating with their partners openly about their experience, and negotiating boundaries and agreements that help protect their relationship (e.g., Deri, 2015; McLean, 2004; Ritchie \& Barker, 2006; Rubinsky, 2018; Visser \& McDonald, 2007; Wolfe, 2003; Wosick-Correa, 2010), and in doing so, are able to capitalize on the positive aspects of their partner engaging in extradyadic relations. If that is the case, then perceiving someone to be romantically interested in one's partner may upset a person, please them, or invoke mixed emotions, and we may expect these reactions to be predicted by one's relationship orientation, with those who are polyamorous experiencing more positive responses, or compersion, in response to a partner's extradyadic relations, and less negative reactions, or jealousy, compared to people in monogamous relationships. However, because people in polyamorous relationships have been shown to experience both jealousy and compersion, we may expect people in polyamorous relationships to report more emotional ambivalence, that is, both positive and negative feelings in response to a partner's extradyadic relations.

\section{Forecasting Emotions}

Despite a good deal of research concerning people's ability to predict emotional responses to future events (e.g., Dunn et al. 2003; Eastwick et al. 2008; Gilbert et al. 1998; Wilson et al. 2000), to our knowledge, no past work has investigated people's tendency to forecast positive and negative reactions to jealousy inducing scenarios, nor has research assessed whether relevant past experiences influence individuals' reactions to such situations. There are reasons to believe that people in polyamorous relationships may forecast more positive and more nuanced emotions than people in monogamous relationships. People in polyamorous relationships have more experience with their partner's engaging in extradyadic romantic experiences and such experiences may reduce the perceived threat and the associated negative 
emotions. More specifically, people tend to overestimate their affective responses to simulated (imagined) situations (Gilbert \& Wilson, 2007) and tend to anticipate less intense reactions to a future event when thinking about relevant past experiences (Buehler \& McFarland, 2001). Accordingly, greater personal experience with a partner's extradyadic behaviors among individuals in monogamous relationships, who will tend to view such jealousy-inducing scenarios negatively, should be associated with expecting a less negative response. In contrast, if people in polyamorous relationships tend to anticipate more compersion in response to jealousyinducing scenarios than people in monogamous relationships, past experiences with such scenarios may temper the expected positive emotional responses.

\section{Effects of Compersion, Jealousy, and Emotional Ambivalence on Relationship Quality}

Past research indicates that compersion and jealousy have complex relationships with relationship satisfaction, with each predicting higher satisfaction in some instances, but often depending on one's gender or relationship configuration (Aumer et al., 2014; Mogilski et al., 2019). For example, Aumer and colleagues (2014) asked participants to imagine a partner's extradyadic interests and found that while men's reactions were largely unrelated to their relationship satisfaction, for single women, and women in open relationships, responses of compersion were positively associated with relationship satisfaction. A similar-though nonsignificant - trend for compersion was also evident among polyamorous women. In contrast to these groups, they further noted that monogamous women with higher jealousy scores and lower compersion scores tended to have higher satisfaction. This trend for jealousy within monogamous women is corroborated by other research which has shown that while jealousy is associated with lower relationship satisfaction when the jealousy is experienced as chronic and ruminative, it is associated with greater satisfaction when it is experienced situationally and in 
response to an actual threat (see Elphinston, Feeney, Noller, Connor, \& Fitzgerald, 2013; Rydell \& Bringle, 2007). Taken together, this may suggest that that experiences of jealousy inducing situations may differentially provoke emotional jealousy and compersion depending on one's relationship orientation, the nature of the jealousy (e.g., whether it is chronic) and that such effects may be more prominent for women.

\section{Current Study}

Building on previous research (Aumer et al., 2014; Balzarini et al., 2017; Balzarini et al., 2018; Mogilski et al., 2017) assessing differences among polyamorous and monogamous partners, and drawing on theories of jealousy, emotional ambivalence, and emotional forecasting, we sought to assess the extent to which experiences of positive and negative reactions to a partner's extradyadic sexual involvement differ among people in polyamorous and monogamous relationships, whether reports of anticipated emotional jealousy and compersion are moderated by people's experiences with either, and whether anticipated responses to a partner's extradyadic sexual and romantic interest is associated with relationship quality.

Because those in monogamous relationships are likely to expect monogamous behavior from their partners (and would likely feel threatened if that expectation were violated), we anticipated that monogamous participants would react more negatively to a hypothetical scenario in which their partner interacts romantically with others than polyamorous participants (H1). As it is an expected part of the relationships polyamorous participants identify with, however, we would expect polyamorous individuals to react more positively to those situations than monogamous individuals (H2).

Additionally, because people tend to overestimate their affective responses to simulated (imagined) situations (Gilbert \& Wilson, 2007) and tend to anticipate less intense reactions to a 
future event when thinking about relevant past experiences (Buehler \& McFarland, 2001); we expected that participants who can recall similar experiences they have actually had may have less extreme expectations about how they will react. Accordingly, we would expect that among monogamous participants, who will tend to view the scenarios negatively, greater personal experience would be associated with expecting a less negative response $(\mathrm{H} 3)$, as it may counter inflated expectations. Likewise, among polyamorous participants, who may tend to view the scenarios positively, greater personal experience would likely be associated with expecting a less positive response to the situation (H4).

We further sought to assess whether positive, negative, and ambivalent affect are associated with relationship quality. If positive and negative affect do predict relationship satisfaction in this study, it's likely that they will conform to the patterns observed in previous research (e.g., Aumer and colleagues, 2014), with satisfaction being negatively related to positive emotions (similar to compersion), and positively related to negative emotions (emotional jealousy) for monogamous women, and we would expect this complexity to extend to more general positive and negative valence emotional responses to situations which might elicit jealousy or compersion, such that the relationship between the emotional responses and satisfaction will depend on gender, likely being significant for women only. More specifically, based on previous research that has shown that greater compersion can at times be associated with higher satisfaction with one's relationship (Aumer et al., 2014), we predicted that relationship satisfaction would be positively associated with positive valence emotions expressed in response to jealousy invoking scenarios (H5) and negatively associated with negative valence emotions (H6). Consistent with past research (Aumer et al., 2014), we would expect these associations to be moderated by gender, such that the associations with positive and negative 
emotions would be significant for women (but not men, H7). We further expected the relationship between satisfaction and emotions to be moderated by individuals' involvement and identification with monogamous or polyamorous relationships. For individuals in monogamous relationships, scenarios that involve a partner engaging in extradyadic sexual or romantic interactions would present a violation of their expectations for that relationship, while individuals in non-monogamous relationships may see the scenarios as potential affirmations of their identities. Based on Aumer and colleagues' (2014) findings, we would expect that monogamous individuals will react more negatively and less positively to the scenarios when they are in more satisfying relationships than when they are in less satisfying relationships. Accordingly, we would expect monogamous participants to experience a negative association between positive valence emotions and satisfaction, and a positive relationship between negative valence emotions and satisfaction, but only for women (H8).

Finally, experiencing ambivalence when required to make a choice is unpleasant (Van Harreveld et al., 2009) and there is evidence that relationships which mix positive and negative feelings are so stressful that they may negatively impact a person's health (Uchino et al., 2012). Given the stress generated by ambivalence in a relationship, we would expect that individuals who imagine both positive and negative emotional reactions to the scenarios (individuals who experience mixed emotions) would experience lower relationship satisfaction (H9). All of the predictions were pre-registered on the OSF prior to conducting analyses. Other hypotheses related to compersion and jealousy were also pre-registered and will be reported in future manuscripts.

\section{Method}

\section{Sample and Procedure}


Our study uses data from two large online convenience samples, examining individuals in polyamorous $(N=3,530)$ and monogamous relationships $(N=1,358)$. For the first sample, participants were told that researchers were interested in investigating the perceptions of partners among individuals in polyamorous relationships. In the second sample, participants were told that the researchers were interested in the perceptions of partners among individuals in monogamous relationships. Participants for both samples were recruited online from various internet forums, dating sites, Lesbian Gay Bisexual Transgender Queer (LGBTQ) groups, and Facebook group pages. Many of these websites and groups were specifically geared toward either polyamorous (first study) or monogamous (second study) audiences, as were the advertisements for recruitment. Recruitment materials specified that participants should be in a polyamorous (first sample) or monogamous (second sample) relationship. Further, participants in polyamorous relationships were asked to indicate whether each partner they listed was aware of and had consented to the participants' other partner(s) (asked separately for each partner). Only participants whose partners were aware of and consented to their other partners were included in the current study in order to provide a clear delineation between polyamory and infidelity. All participants were volunteers and had to be 17 years of age or older, speak English fluently, and self-identify as currently in a polyamorous or monogamous relationship.

Prospective participants were provided a link that re-directed them to a survey hosted on Qualtrics. Participants were asked to list the initials of their current partner (first two partners if polyamorous) and to complete a series of measures, including the measures evaluated in the current study (outlined below). Monogamous and polyamorous participants answered the same questions in the same order. More recruitment details can be found in previous publications 
using this dataset (Balzarini et al., 2017; 2018; 2019) and more information about the measures and procedures can be found on the $\underline{\mathrm{OSF}}$.

\section{Participants}

Within the pooled polyamorous and monogamous sample $(N=4,888)$, most participants were in their mid-30's (polyamorous $M=34.36$, monogamous $M=33.41$ ), identified as white (polyamorous: $88.6 \%$, monogamous: $76.7 \%$ ) cisgender women (polyamorous: $56.6 \%$, monogamous: 60.8\%) who were either heterosexual (polyamorous: $36.1 \%$, monogamous: $67.7 \%$ ) or bisexual (polyamorous: $32.1 \%$, monogamous: $13.3 \%$ ), and married or in civil unions/domestic partnerships (polyamorous: 49.8\%, monogamous: $37.3 \%$ ). For more information about the demographics, see Table 1.

\section{Measures}

Monogamous participants completed the following measures for a single partner while polyamorous participants were asked to complete these measures for two concurrent partners. That is, polyamorous participants were asked for the initials of two concurrent partners, and using piped text, each partner's initials was inserted into future questions to increase clarity about which questions were in reference to each partner. For a complete listing of the measures and more information about the procedure, please see the OSF.

Relationship Satisfaction. The Investment Model Scale (Rusbult, Martz, \& Agnew, 1998) was used to assess relationship satisfaction (e.g., "I feel satisfied with our relationship"). Three items were rated on a 9-point Likert-type scale, with responses ranging from 1 (do not agree at all) to 9 (agree completely). Items were mean aggregated with higher scores indicating more relationship satisfaction (monogamous $\alpha=0.85$, primary $\alpha=0.81$, and secondary $\alpha=$ 0.85). 
Anticipated Positive and Negative Affect. To examine anticipated positive and negative experiences in response to extradyadic partner involvement, participants were asked to rate their likelihood of experiencing a number of affective reactions (e.g., happiness, excitement, anger, sadness) to six hypothetical scenarios involving a partner's extradyadic romantic relations (e.g., "If [partner] fell in love with another person..." "If [partner] was having sex regularly with another person...”) that were developed by authors of the current paper. Participants were asked to respond to 11 items pertaining to each scenario. For each of the scenarios, ten items asked participants to rate their likelihood of experiencing different reactions to the situation, and one item asked participants to indicate whether they had experienced the situation described (e.g., participants would be prompted with, "If my partner fell in love with another person, I would feel..." The emotions chosen for the anticipated reaction items were drawn from the Positive and Negative Affect Schedule (PANAS; Watson, Clark, \& Tellegen, 1988).

Four of the emotional response items asked participants to estimate the likelihood that they would feel positive emotional reactions (excitement, happiness, joy, or enthusiasm) in response to the situations described. Response options ranged from 1 (not at all) to 7 (very much). Responses to these items were averaged across the six scenarios to create a 24 -item composite measure of anticipated positive affect (monogamous relationships: $\alpha=0.98$, primary relationships: $\alpha=0.98$, secondary relationships: $\alpha=0.98$ ), for which high scores reflect a high expectation that the respondent would react positively to extradyadic partner involvement.

Another four of these items asked participants to estimate the likelihood that they would feel negative emotional reactions (jealousy, fear, sadness, or anger) on a seven-point scale from 1 ("Not at All") to 7 ("Very Much"). A measure of anticipated negative affect (monogamous relationships: $\alpha=0.96$, primary relationships: $\alpha=0.97$, secondary relationships: $\alpha=0.98$ ) was 
calculated by mean averaging responses to these items, with higher scores reflecting a high expectation that the respondent would react negatively to extradyadic partner involvement. For more information about the scale validation, please see the Supplemental Materials.

Personal Experience. After rating their potential emotional responses to each scenario, they were also asked to indicate whether this had ever happened to them with their partner with a "yes" or "no" response). The responses to these six "yes" or "no" items were tallied and divided by six to create an index of personal experience with extradyadic partner involvement (monogamous relationships: $\alpha=0.80$, primary relationships: $\alpha=0.81$, secondary relationships: $\alpha$ $=0.84$ ) ranging from 0 to 1 , with greater scores indicating more personal experience, and 0 representing complete lack of experience with extradyadic partner involvement.

\section{Analytic Plan}

Seven linear regressions were performed to test the study's hypotheses, using the combined data from the monogamous and polyamorous respondents. Since polyamorous participants completed the measures multiple times, all analyses were conducted twice: once comparing polyamorous participants' first partner to monogamous partners (primary analysis), and again comparing polyamorous participants responses for their second partners to monogamous ratings.

To test the first four hypotheses, the first two regression models examined whether relationship type (monogamous or polyamorous), experience, and the interaction between relationship type and past experience were associated with how much positive and negative affect a person would anticipate. Next, to test hypotheses five, six, seven, and eight, the third regression model predicted relationship satisfaction using relationship type (monogamous vs. 
polyamorous), gender, positive affect, negative affect, and five (two-way) interactions among those predictor variables.

All regression model predictors were standardized by mean centering, and the interaction terms were calculated using the standardized scores, in order to minimize the impact of collinearity on the interactions in our regressions. All regression models reported throughout the rest of this paper utilize standardized scores. To control for the experiment-wise error rate in hypothesis testing associated with conducting a large number of statistical tests (Kirk, 1982), the criteria for statistical significance for our pre-registered hypotheses was corrected by using the Bonferroni method; dividing $\alpha=.05$ by the number of tests proposed in the pre-registration (.05 / $17=.0029)$. Therefore, the $\mathrm{p}$-value used across these analyses was set at $p<.0029$ level rather than the typical $p<.05$ level. The analytic approach was pre-registered and can be found on the

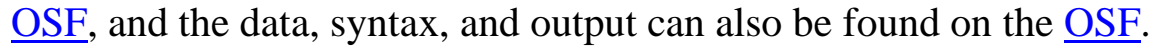

\section{Results}

Descriptive statistics for this study's key measures are presented in Table 2, broken down by relationship type.

\section{Comparing Positive and Negative Affective Responses and Examining the Effect of Personal Experience}

We first examined whether the anticipation of negative emotional responses (e.g., jealousy, anger, sadness, and fear) to potentially jealousy-inducing scenarios was associated with one's relationship orientation (monogamous versus polyamorous), experience with the scenarios in real-life, and their interaction. Regression coefficients are reported in Table 3. Consistent with expectations (H1), monogamous individuals anticipated more negative emotions in response to the hypothetical scenarios of their partner engaging in extradyadic sexual and emotional relations 
(primary: $B=2.28, S E=0.09, p<.001$; secondary: $B=2.55, S E=0.09, p<.001$ ). However, while we expected real-life experience to reduce anticipated negative affect for monogamous individuals (H3), in both analyses, experience predicted lower anticipated negative affect for monogamous and polyamorous individuals (primary: $B=-1.15, S E=0.09, p<.001$; secondary: $B=-1.25, S E=0.11, p<.001)$. The interaction between relationship type and experience upon expectations of negative affect (primary: $B=-0.59, S E=0.24, p=0.016$; secondary: $B=-0.49$, $S E=0.25, p=.049)$ was not significant in either analysis, however.

Next, we examined anticipated positive emotional responses (e.g., excitement, happiness, joy, enthusiasm) to these scenarios. Regression coefficients are reported in Table 4. For both the primary and secondary analyses, being polyamorous (primary: $B=2.53, S E=0.17, p<.001$; secondary: $B=2.62, S E=0.09, p<.001$ ) and having real-life experience with the scenarios (primary: $B=2.21, S E=0.42, p<.001$; secondary: $B=2.14, S E=0.09, p<.001$ ) predicted higher anticipated positive affect. Consistent with expectations (H2), polyamorists anticipated more positive affect than monogamists. However, rather than decreasing anticipated positive affect among polyamorous respondents as expected $(\mathrm{H} 4)$, real-life experience with the scenarios predicted higher anticipated positive affect for both polyamorous and monogamous individuals. Furthermore, the interaction between relationship type and experience was significant and negative in the secondary analysis $(B=-0.81, S E=0.25, p=.001)$. This interaction indicated that, in the context of secondary relationships, first-hand experience with jealousy-inducing situations was less impactful for polyamorous individuals than it was for monogamous individuals reports of their partners.

Effects of Positive, Negative, and Ambivalent Emotional Responses on Relationship Quality 
Then, we examined the association between relationship satisfaction and reports of positive affect, negative affect, and emotional ambivalence. Regression coefficients are reported in Table 5. Consistent with expectations (H5), anticipating positive emotional responses to the situations was a significant predictor of satisfaction (primary: $B=0.17, S E=0.05, p=.001$; secondary: $B=0.23, S E=0.07, p=.001)$. Contrary to expectations, however, lower satisfaction was not associated with (H6) negative emotional responses (i.e., jealousy) or (H9) ambivalent emotional responses (e.g., experiencing positive and negative emotional responses). Furthermore, the expected interactions with $(\mathrm{H} 7)$ gender and $(\mathrm{H} 8)$ relationship type did not emerge. Furthermore, monogamous relationships were more satisfying than secondary relationships $(B=0.23, S E=0.07, p<.001)$ but not more satisfying than primary relationships, which is consistent with previous research (see Balzarini et al., 2019; Mogilski et al., 2017).

\section{Discussion}

Emotional reactions towards a partner's extradyadic romantic interests are assumed to be negative and characterized by jealousy, or an emotional state that arises over the perception of a threat to one's relationship (Chung \& Harris, 2018; Harris \& Darby, 2010; Parrott, 1991; Parrott \& Smith, 1993; White \& Mullen, 1989). Yet, the current research suggests that reactions may also be positive, and involve compersion, or taking joy in one's partner's pleasure in other sexual and relational encounters, though this may depend on one's relationship arrangement and agreements for exclusivity. More specifically, people in polyamorous relationships, or relationships that afford individuals the opportunity to seek out multiple sexual and romantic relationships with the consent of all partners, report less negative affect including emotional jealousy and more compersion-consistent positive affect when imagining their partners engaging in extradyadic relations compared to individuals in monogamous relationships. Furthermore, 
personal experience involving a partner's extradyadic romantic interests, which was higher among people in polyamorous relationships, was associated with more positive affect and less negative affect, with experience predicting greater increases in positive affect among monogamous than polyamorous participants. Lastly, while anticipated positive affective responses were associated with greater relationship satisfaction negative affective responses and ambivalence were not associated with relationship satisfaction.

\section{Comparing Positive and Negative Affective Responses}

Consistent with our predictions, we found that experiences of positive and negative affect were shaped by one's relationship orientation, with those who identify as polyamorous reporting fewer negative emotions and less emotional jealousy in response to a partners hypothetical extradyadic sexual and romantic interests, and instead, they anticipated more positive emotions, or feelings of compersion. These findings are consistent with past research documenting differences in compersion and jealousy based on relationship status (e.g., Aumer et al., 2014), and are in line with other recent research that has shown that the consent to seek out extradyadic partners may influence experiences of compersion and jealousy. That is, Mogilski and colleagues (2019) argue that consent may alter the parameters by which individuals evaluate extradyadic behavior as a cue of threat to their relationship (e.g., a partner's dishonesty vs. a partner's inclination to invest into an extradyadic relationship). Furthermore, past research has also shown that individuals in polyamorous relationships work to overcome their jealousy through open communication, negotiating, and so forth (.g., Deri, 2015; McLean, 2004; Ritchie \& Barker, 2006; Rubinsky, 2018; Visser \& McDonald, 2007; Wolfe, 2003; Wosick-Correa, 2010), and although speculative, in doing so, this may actually promote compersion among individuals who engage in relationships with multiple partners. More specifically, it is possible that 
communicating about jealousy, openly discussing a partner's extradyadic desires, and establishing agreements and boundaries that are consensually agreed upon, may make it safer, and less threatening to consider a romantic partner engaging in alternative relationships, and when these desires are discussed prior to engaging in extradyadic relationships, it may alleviate suspicion and worries about being left for a new partner (see Rubinsky, 2018).

\section{Personal Experiences with Jealousy Inducing Situations}

Affective forecasting research suggests that personal experience tempers the anticipation of intense emotions (Buehler \& McFarland, 2001). Based on past research (e.g., Gilbert \& Wilson, 2007), in this study, we expected that real-life experience would lead monogamous participants to anticipate less negative affect and polyamorous participants to anticipate less positive affect; but contrary to our expectations, this was not the case. That is, although monogamous participants anticipated more negative affect and polyamorous individuals anticipated more positive affect, results suggest that personal experience does not just yield more temperate emotional reactions. Instead, monogamous and polyamorous individuals alike anticipated less negative affect but more positive affect when they had encountered the situations in real life. In hindsight, the contradictory effects make intuitive sense, such that when individuals acquire greater experience with a partner expressing or engaging in extradyadic relations, and especially when the outcome was positive, individuals may adjust their appraisals of future reactions accounting for their past experience and rendering their future anticipated responses to be more nuanced, including less negative reactions, and more positive ones. This may be especially true if the experience brought about positive changes in the relationship. So, for example, if an individual had prior experiences with a partner expressing extradyadic interests, but the couple is still together, we might assume that the couple successfully navigated 
and worked through their partner's engagement or interest in extradyadic relations, and doing this may have brought the couple closer together and reaffirmed the relationship security.

The only interaction between relationship type and personal experience that was evident was for positive affective reactions, such that the positive impact of personal experience was evident for both monogamous and polyamorous participants, but even more so for monogamous participants. This may be due to the fact that there is disparity in the degree to which individuals in monogamous and polyamorous relationships expect compersion. For example, the average anticipated positive affect score for monogamous participants was extraordinarily low, barely one standard deviation above the scale's minimum, while scores sit at the opposite end of the scale for polyamorous participants. As a result, factors that would increase anticipated positive affect scores for polyamorous individuals would immediately encounter a ceiling effect imposed by the scale's limitations, making it difficult to interpret the apparent interaction between relationship type and real-life experience with jealousy-inducing situations. Furthermore, having past experiences, regardless of how desirable they were, may influence one's perception of the likelihood of this event occurring in the future. More specifically, people believe that the affective reactions to an outcome depends not only on the desirability of the outcome but also on the probability of its occurrence (e.g., Loewenstein \& Lerner, 2003; Mellers, Schwartz, Ho, \& Ritov, 1997). As such, while having a partner seek out extradyadic relations may in general be perceived as a loss, or a generally negative situation, especially among monogamous individuals, people believe losses hurt more when they are unanticipated than when they are anticipated. Conversely, gains, or positive situations and experiences in this case, are almost always pleasurable, but are more pleasurable when they are unanticipated than when they are 
anticipated. As such, it may be the case that individuals in monogamous relationships are more impacted by past experiences in part because past experiences countered their expectations.

Overall, this research suggests that reactions to a partner's extradyadic interests do in fact differ among people in monogamous and polyamorous relationships, and that past experiences with such situations also influence projected forecasted emotions, with individuals who have encountered such situations anticipating more compersion, or positive affective reactions, and less jealousy, or negative affective responses. This is important because nearly all of the research on jealousy and people's reactions to partner's extradyadic relations has assumed that responses almost exclusively involve jealousy and other negatively valanced emotions, and that experiences of jealousy are immutable (Mint, 2004; Stohlman-Vanderveen, 2019; Tucker, 2013). Indeed, this notion is embedded in the very ways we assess jealousy, with measures like the Multidimensional Jealousy Scale (Pfeiffer \& Wong, 1989) assuming that a lack of negative reactions is indicative of low jealousy, but not considering the fact that this may be representative of compersion, or the expression of positive emotions. This is also important because many of the scales used to assess reactions to jealousy inducing situations are bipolar, and do not allow participants to rate their positive and negative reactions independently. For example, many attempts to assess jealous reactions to extradyadic interests involve forced choice paradigms where individuals have to choose between the worst of two options (e.g., Buss et al., 1992; 1999; Mogilski, et al., 2019). Given the results of this study, this approach fails to capture the potential complexity of people's actual experiences, because, as this research suggests, reactions can be negative, positive, or a blend of the two. Because of this, past research may have biased our understanding of people's reactions to partner's extradyadic interests by limiting assessments to negative affective responses. 


\section{Effects of Positive, Negative and Ambivalent Emotional Responses on Relationship Quality}

The current study also sought to assess whether positive affect, negative affect, and emotional ambivalence influenced reports of relationship quality and we found generally weak effects in support of this idea. That is, anticipating positive emotional responses to a partner's extradyadic interests were associated with higher relationship satisfaction, but expectations about negative reactions, or ambivalent reactions did not influence reports of relationship quality. While the results for negative affect are inconsistent with some of the past research examining associations between jealousy and relationship quality among those in polyamorous relationships (e.g., Aumer et al., 2014; Mogilski et al., 2019), it is important to position these findings with past literature that has largely been mixed. More specifically, other past work examining jealousy and relationship quality among presumably monogamous samples (orientation not always specified) has presented mixed effects (Demirtas \& Donmez, 2006), with some research showing jealousy is associated with positive effects, such as higher relational satisfaction and commitment (e.g., Mathes, 1986; Rydell et al., 2004), and yet also showing that jealousy is associated with negative relationship outcomes, like relational dissatisfaction and uncertainty (e.g., Barelds \& Barelds-Dijkstra, 2007; Bevan, 2004; Guerrero \& Eloy, 1992), perhaps depending on how chronic and ruminative the jealousy is (e.g., Elphinston et al., 2013).

\section{Limitations}

Although the items included in the anticipated positive and negative affect scales met reliability standards, the mean responses for polyamorous individuals tend to be very high on the positive affect scale and very low on the jealousy scale, while this pattern is clearly reversed for monogamous participants. Unfortunately, the groups cluster so closely to their respective ends of the anticipated emotion scales that both scales may be subject to floor effects and ceiling effects. 
This may suggest a general dilemma that stems from studying two very different populations with the same measure. Future research should examine individuals with more diverse relationship orientations, including those in open and swinging relationships, as findings for relationships that may be more focused on sexual experiences (e.g., swinging) may elicit less strong responses resulting in less likelihood of floor or ceiling effects. A second shortcoming stems from the prospective reports of jealousy and compersion used in the current study, and in most studies examining responses to extradyadic sexual and romantic interests and infidelity (e.g., Aumer et al., 2014; DeSteno, 2004; Mogilski et al., 2019; Salovey, 1991). These studies essentially assess participants' predictions about how they would feel, not their emotional responses to a partner's actual extradyadic interests. As such, it is unclear how accurately people's responses represent their actual emotional reactions to jealousy-inducing situations. An additional limitation is that among those in polyamorous relationships we assessed only individuals' relationships with two romantic partners. It would also be useful to consider polyamorous relationships from a systemic perspective, considering the interrelations of all individuals in a polyamorous network, and the broader social system in which polyamorous relationships are embedded and how this may shape people expectations for and experiences of jealousy and compersion in a way that differs from people in monogamous relationships. Finally, despite our efforts to address some relevant demographic and relational factors (e.g., gender and relationship orientation), we did not have enough diversity in race and other potentially important demographic factors to test whether the association of positive and negative reactions to extradyadic partner involvement and its association with relationship quality were widely generalizable.

\section{Conclusions}


If a person is asked to describe their emotions in the immediate present, we might reasonably expect states of mixed emotions to be rare - only under very particular circumstances might a person feel seemingly contradictory emotions like jealousy and compersion at the exact same moment in time. However, if that same person is asked to imagine what emotions they might feel in response to a hypothetical situation, we should expect participants to imagine not only their feelings at that future moment, but their feelings in the moment after that, and the moment after that. We might also expect them to imagine multiple different incarnations of the hypothetical situation, each of which may give rise to different expectations about how they will react. Unfortunately, measures that are commonly used to assess jealousy, like the emotional subscale of the Multidimensional Jealousy Scale (Pfeiffer \& Wong, 1989), consider positive and negative emotional responses as two ends of a single emotional response variable. This approach discounts the possibility that a person may experience mixed emotions in the present reality or anticipate more than one possible response to a hypothetical future. As this study demonstrates, such bipolar measures may be inadequate for the study of jealousy, especially when considering populations that may experience or respond to jealousy in ways that are not consistent with broader cultural expectations. Indeed, these results further demonstrate that individuals can experience both positive and negative reactions to a partner's extradyadic relations, and these reactions are influenced by actual experience and projection of their responses to anticipated future events, with real-life experiences shaping peoples anticipated emotional reactions. 


\section{References}

Afifi, W. S., Falato, W. L., \& Weiner, J. L. (2001). Identity concerns following a severe relational transgression: The role of discovery method for the relational outcomes of infidelity. Journal of Social \& Personal Relationships; 18, 291-308.

AlShawaf, L., Conroy-Beam, D., Asao, K., \& Buss, D. M. (2016). Human emotions: An evolutionary psychological perspective. Emotion Review, 8, 173-186.

Altman, I., Vinsel, A., \& Brown, B. B. (1981). Dialectic conceptions in social psychology: An application to social penetration and privacy regulation. In L. Berkowitz (Ed.), Advances in Experimental Social Psychology: Volume 14 (pp. 107-160). New York, NY: Academic Press.

An, S., Ji, L-J, Marks, M., \& Zhang, Z. (2017). Two sides of emotion: Exploring positivity and negativity in six basic emotions across cultures. Frontiers in Psychology, 8. Retrieved from https://www.ncbi.nlm.nih.gov/pmc/articles/PMC5397534/

Anapol, D. T. (1998). Compersion: Meditations on using jealousy as a path to unconditional love. San Rafael, CA: IntinNet Resource Center.

Aumer, K., Bellew, W., Ito, B., Hatfield, E., Heck, R. (2014). The happy green eyed monogamist: Role of jealousy and compersion in monogamous and non-traditional relationships. Electronic Journal of Human Sexuality, 17, 77-88.

Balzarini, R. N., Campbell, L., Kohut, T., Holmes, B. M., Lehmiller, J. J., Harman, J. J., Atkins, N. (2017). Perceptions of primary and secondary relationships in polyamory. PlosOne, 12, e0177841. 
Balzarini, R. N., Dharma, C., Kohut, T., Campbell, L., Holmes, B. M., Lehmiller, J. J., \& Harman, J. J. (2018). Demographic comparison of American individuals in polyamorous and monogamous relationships. Journal of Sex Research, 56, 681-694.

Balzarini, R. N., Dharma, C., Kohut, T., Campbell, L., Lehmiller, J. J., Harman, J. J., \& Holmes, B. M. (2019). Comparing relationship quality across different types of romantic partners in polyamorous and monogamous relationships. Archives of Sexual Behavior, 48, 17491767.

Barrett, L. F., \& Bliss-Moreau, E. (2009). Affect as a psychological primitive. In M. P. Zanna (Ed.). Advances in Experimental Social Psychology, 41, 167-218.

Bittman, M. \& Pixley, J. (1997). The Double Life of the Family. Sydney, AU: Allen \& Unwin.

Blanchflower, D., \& Oswald, A. (2004). Money, sex and happiness. An empirical study. Scandinavian Journal of Economics, 106, 393-415.

Brown, A. (2017). Five key findings about LGBT Americans. Pew Research Center: Fact Tank, Retrieved from https://www.pewresearch.org/fact-tank/2017/06/13/5-key-findingsabout-lgbt-americans/

Buss, D. M. (2002). Human mate guarding. European Neuroendocrinology Letters, 23, 23-29.

Buss, D. M., Larsen, R. J., Westen, D., \& Semmelroth, J. (1992). Sex differences in jealousy: Evolution, physiology and psychology. Psychological Science, 3, 251-255.

Buss, D. M., Shackelford, T. K., Kirkpatrick, L. A., Choe, J. C., Lim, H. K., Hasegawa, M., et al. (1999). Jealousy and the nature of beliefs about infidelity: tests of competing hypotheses about sex differences in the United States, Korea, and Japan. Personal Relationships, 6, $125-150$. 
Buss, D. M., Shackelford, T. K., \& McKibbin, W. F. (2008). The Mate Retention InventoryShort Form (MRI-SF). Personality and Individual Differences, 44, 322-334.

Chung, M., \& Harris, C. R. (2018). Jealousy as a specific emotion: The dynamic functional model. Emotion Review, 10, 272-287.

Conley, T. D., Mastick, J. L., Moors, A. C., \& Ziegler, A. (2017). Investigation of consensually nonmonogamous relationships: Theories, methods and new directions. Perspectives on Psychological Science, 12, 205-232.

Conley, T. D., Moors, A. C., Matsick, J. L., \& Ziegler, A. (2013). The fewer the merrier?: Assessing stigma surrounding consensually non-monogamous romantic relationships. Analyses of Social Issues and Public Policy, 13, 1-30.

Deri, J. (2015). Love's refraction: Jealousy and compersion in queer women's polyamorous relationships. Toronto, ON: University of Toronto Press.

DeSteno, D. A. (2004, May). New perspectives on jealousy: An integrative view of the most social of social emotions. Paper presented at the meeting of the American Psychological Society, Chicago, IL.

Dunbar, L. J. (2008). A conflict between distance and closeness: The mother's bittersweet experience of becoming separate from her toddler. International Journal of Infant Observation and Its Applications, 11, 77-88.

Dunn, E. W., Wilson, T. D., \& Gilbert, D. T. (2003). Location, location, location: The misprediction of satisfaction in housing lotteries. Personality and Social Psychology Bulletin, 29, 1421-1432. 
Eastwick, P. W., Finkel, E. J., Krishnamurti, T., \& Loewenstein, G. (2008). Mispredicting distress following romantic breakup: Revealing the time course of the affective forecasting error. Journal of Experimental Social Psychology, 44, 800-807.

Edlund, J. E., Heider, J. D., Scherer, C. R., Farc, M. M., \& Sagarin, B. J. (2006). Sex differences in jealousy in response to actual infidelity. Evolutionary Psychology, 4, 462-470.

Elphinston, R. A., Feeney, J. A., \& Noller, P. (2011). Measuring romantic jealousy: Validation of the multidimensional jealousy scale in Australian samples. Australian Journal of Psychology, 63, 243-251.

Elphinston, R. A., Feeney, J. A., Noller, P., Connor, J. P., \& Fitzgerald, J. (2013). Romantic jealousy and relationship satisfaction: The costs of rumination. Western Journal of Communication, 77, 293-304.

Gilbert, D. T., Pinel, E. C., Wilson, T. D., Blumberg, S. J., \& Wheatley, T. P. (1998). Immune neglect: A source of durability bias in affective forecasting. Journal of Personality and Social Psychology, 75, 617-638.

Guerrero, L. K., \& Eloy, S. V. (1992). Relational satisfaction and jealousy across marital types. Communication Reports, 5, 23-31.

Harris, C. R. (2000). Psychophysiological responses to imagined infidelity: The specific innate modular view of jealousy reconsidered. Journal of Personality and Social Psychology, $78,1082-1091$.

Harris, C. R. (2003). Factors associated with jealousy over real and imagined infidelity: An examination of the social-cognitive and evolutionary psychology perspectives. Psychology of Women Quarterly, 27, 319-329. 
Harris, C. R., \& Darby, R. S. (2010). Jealousy in adulthood. In S. L. Hart \& M. Legerstee (Eds.), Handbook of jealousy: Theory, research, and multidisciplinary approaches (pp. 547571). Oxford, UK: Wiley Blackwell.

Haupert, M., Gesselman, A., Moors, A., Fisher, H., \& Garcia, J. (2017). Prevalence of experiences with consensual non-monogamous relationships: Findings from two nationally representative samples of single Americans. Journal of Sex \& Marital Therapy, 43, 424-440.

Hui, C. M., Fok, H. K., \& Bond, M. H. (2009). Who feels more ambivalence? Linking dialectical thinking to mixed emotions. Personality and Individual Differences, 46, 493-498.

Joel, S., MacDonald, G., \& Page-Gould, E. (2018). Wanting to stay and wanting to go: Unpacking the content and structure of relationship stay/leave decision processes. Social Psychological and Personality Science, 9, 631-644.

Kohut, T., Balzarini, R. N., Lehmiller, J. J., Harman, J. J., \& Holmes, B. M. (November 18, 2016). Can jealousy be adequately measured in polyamorous relationships with traditional closed-ended assessments?. Symposium presentation at Sex Rising: Revolutionary and Emerging Voices in Sexual Science, 2016 Annual Meeting of SSSS, Phoenix, Arizona.

Kuhle, B. X. (2011). Did you have sex with him? Do you love her? An in vivo test of sex differences in jealous interrogations. Personality and Individual Differences, 51, 10441047.

Larsen, J. T., \& Green, J. D. (2013). Evidence for mixed feelings of happiness and sadness from brief moments in time. Cognition \& Emotion, 27, 1469-1477. 
Larsen, J. T., \& McGraw, A. P. (2011). Further evidence for mixed emotions. Journal of Personality and Social Psychology, 100, 1090-1110.

Larsen, J. T., McGraw, A. P., \& Cacioppo, J. T. (2001). Can people feel happy and sad at the same time? Journal of Personality and Social Psychology, 81, 684-696.

Larsen, J. T., \& McGraw, A. P. (2014). The case for mixed emotions. Social and Personality Psychology Compass, 8, 263-274.

Levine, E. C., Herbenick, D., Martinez, O., Fu, T., \& Dodge, B. (2018). Open relationships, nonconsensual nonmonogamy, and monogamy among U.S. adults: Findings from the 2012 National Survey of Sexual Health and Behavior. Archives of Sexual Behavior, 47, $1439-1450$.

Masci, D., Brown, A., \& Kiley, J. (2017). 5 facts about same-sex marriage. Pew Research Center. Retrieved from https://www.pewresearch.org/fact-tank/2017/06/26/same-sexmarriage/

Mathes, E. (1986). Jealousy and romantic love: A longitudinal study. Psychological Reports, 58, $885-886$.

McLean, K. (2004). Negotiating (non) monogamy: Bisexuality and intimate relationships. Journal of Bisexuality, 4, 83-97.

Mint, P. (2004). The power dynamic of cheating. Journal of Bisexuality, 4, 55-76.

Mogilski, J. K., Reeve, S. D., Nicolas, S. C. A., Donaldson, S. H., Mitchell, V. E., Welling, L. L. M. (2019). Jealousy, consent, and compersion within monogamous and consensually non-monogamous romantic relationships. Archives of Sexual Behavior, 48, 1811-1828.

Moors, A. C. (2016). Has the American public's interest in information related to relationships beyond "the couple" increased over time? Journal of Sex Research, 54, 677-684. 
O’Neil, R. M. (2007). A caution regarding rules of thumb for Variance Inflation Factors. Quality \& Quantity, 41, 673-690.

Parrott, W. G. (1991). The emotional experiences of envy and jealousy. In P. Salovey (Ed.), The psychology of jealousy and envy (pp. 3-30). New York, NY: Guilford Press.

Parrott, W. G., \& Smith, R. H. (1993). Distinguishing the experiences of envy and jealousy. Journal of Personality and Social Psychology, 64, 906-920.

Pfeiffer, S. M., \& Wong, P. T. P. (1989). Multidimensional jealousy. Journal of Social and Personal Relationships, 6, 181-196.

Ritchie, A. \& Barker, M. (2006). 'There aren't words for what we do or how we feel so we have to make them up': Constructing polyamorous languages in a culture of compulsory monogamy. Sexualities, 9, 584-601.

Rothman, N., Pratt, M. G., Rees, L., \& Vogus, T. (2016). Understanding the dual nature of ambivalence: Why and when ambivalence leads to good and bad outcomes. Academy of Management Annals, 11, 661-698.

Rubin, J. D., Moors, A. C., Matsick, J. L., Ziegler, A., \& Conley, T. D. (2014). On the margins: Considering diversity among consensually non-monogamous relationships. Journal für Psychologie, 22, 1-23.

Rubinsky, V. (2018). Bringing up the Green-Eyed Monster: Conceptualizing and Communicating Jealousy with a Partner Who Has Other Partners. The Qualitative Report, 23, 1441-1455.

Rusbult, C. E. (1983). A longitudinal test of the investment model: The development (and deterioration) of satisfaction and commitment in heterosexual involvements. Journal of Personality and Social Psychology, 45, 101-117. 
Rusbult, C. E., Martz, J. M., \& Agnew, C. R. (1998). The investment model scale: Measuring commitment level, satisfaction level, quality of alternatives, and investment size. Personal Relationships, 5, 357-391.

Ryan, C., \& Jetha, C. (2010). Sex at dawn: How we mate, why we stray, and what it means for modern relationships. New York, NY: Harper Perenial.

Rydell, R. J., McConnell, A. R., \& Bringle, R. G. (2004). Jealousy and commitment: Perceived threat and the effect of relationship alternatives. Personal Relationships, 11, 451-468.

Salovey, P. (1991). The psychology of jealousy and envy. New York, NY: Guilford Press.

Sheff, E. (2013). Jealousy and compersion with multiple partners-How polys deal with jealousy and feel happy when their lover loves someone else. Psychology Today. Retrieved from https ://www.psych ology today .com/blog/the-polyamorists-nextdoor/20131 2/jealo usyand-compersion-multiple-partners-1

Stacey, J. (1996). In the Name of the Family: Rethinking Family Values in the Postmodern Age. Boston, MA: Beacon Press.

Taylor, P., Funk, C., \& Clark, A. (2007). Generation gap in values, behaviors: As marriage and parenthood drift apart, public is concerned about social impact. Pew Research Center. Retrieved from http://www.pewsocialtrends.org/2007/07/01/as-marriage-and-parenthooddrift-apart-public-is-concerned-about-social-impact/

Thompson, A. E., Zimmerman, C. N., Kulibert, D., \& Moore, E. (2017). Sex differences and the effect of rival characteristics on adults' judgments of hypothetical infidelity. Evolutionary Psychological Science, 3, 97-108.

Tucker, J. (2013). Taming the Green-Eyed Monster: On the need to rethink our cultural conception of jealousy, Yale J.L. \& Feminism, 217, 240-241. 
Vantoch, V. (2007). The Threesome Handbook: A Practical Guide to Sleeping with Three. Hachette Books, New York, NY.

Visser, R., \& McDonald, D. (2007). Swings and roundabouts: Management of jealousy in heterosexual 'swinging' couples. British Journal of Social Psychology, 46, 459-476.

Watson, D., Clark, L., \& Tellegen, A. (1988). Development and validation of brief measures of positive and negative affect: The PANAS scales. Journal of Personality and Social Psychology, 54, 1063-1070.

White, G. L., \& Mullen, P. E. (1989). Jealousy: Theory, research, and clinical strategies. New York, NY: Guilford Press.

Wilson, T. D., Wheatley, T. P., Meyers, J. M., Gilbert, D. T., \& Axsom, D. (2000). Focalism: A Source of durability bias in affective forecasting. Journal of Personality and Social Psychology, 78, 821-836.

Wolfe, L. P. (2003). Jealousy and transformation in polyamorous relationships. Doctoral dissertation, The Institute for Advanced Study of Human Sexuality, San Francisco, CA. Retrieved from http://drleannawolfe.com/dissertation.pdf

Wosick-Correa, K. (2010). Agreements, rules and agentic fidelity in polyamorous relationships. Psychology \& Sexuality, 1, 44-61. 


\section{Tables}

Table 1.

Basic Demographics of Participants

\begin{tabular}{|c|c|c|}
\hline & Polyamorous & Monogamous \\
\hline Gender & $(N=3521)$ & $(N=1209)$ \\
\hline Female & $56.7 \%$ & $68.2 \%$ \\
\hline Male & $35.8 \%$ & $30.3 \%$ \\
\hline Trans* & $2.0 \%$ & $0.4 \%$ \\
\hline Other & $5.4 \%$ & $1.1 \%$ \\
\hline Sexual Orientation & $(N=3517)$ & $(N=1208)$ \\
\hline Heterosexual & $36.2 \%$ & $76.2 \%$ \\
\hline Lesbian/Gay & $4.2 \%$ & $4.6 \%$ \\
\hline Bisexual & $32.1 \%$ & $13.3 \%$ \\
\hline Pansexual & $18.8 \%$ & $3.3 \%$ \\
\hline Other & $8.6 \%$ & $2.6 \%$ \\
\hline Ethnicity* & $(\mathrm{N}=3530)$ & $(\mathrm{N}=1358)$ \\
\hline Asian & $2.3 \%$ & $5.3 \%$ \\
\hline African & $2.2 \%$ & $1.5 \%$ \\
\hline Hispanic & $4.9 \%$ & $2.8 \%$ \\
\hline Native & $3.5 \%$ & $1.1 \%$ \\
\hline Pacific Islander & $0.4 \%$ & $0.4 \%$ \\
\hline White & $88.6 \%$ & $76.7 \%$ \\
\hline Multiracial & $5.4 \%$ & $3.5 \%$ \\
\hline Other & $3.4 \%$ & $2.2 \%$ \\
\hline Relationship & $(\mathrm{N}=3530)$ & $(\mathrm{N}=1358)$ \\
\hline Married & $36.7 \%$ & $29.7 \%$ \\
\hline Civil Union & $13.1 \%$ & $7.6 \%$ \\
\hline Separated & $4.8 \%$ & $0.9 \%$ \\
\hline Divorced & $15.2 \%$ & $4.9 \%$ \\
\hline Widowed & $1.1 \%$ & $0.6 \%$ \\
\hline Never Married & $38.0 \%$ & $47.0 \%$ \\
\hline
\end{tabular}

Note: *Categories were not mutually exclusive. 
Table 2.

Means and Standard Deviations for Key Measures

\begin{tabular}{|c|c|c|c|c|c|c|c|}
\hline & \multirow[b]{2}{*}{ Scale } & \multicolumn{2}{|c|}{$\begin{array}{c}\text { Primary } \\
\text { Relationships } \\
(\mathrm{N}=1690)\end{array}$} & \multicolumn{2}{|c|}{$\begin{array}{c}\text { Secondary } \\
\text { Relationships } \\
(\mathrm{N}=1081)\end{array}$} & \multicolumn{2}{|c|}{$\begin{array}{l}\text { Monogamous } \\
\text { Relationships } \\
\qquad(\mathrm{N}=616)\end{array}$} \\
\hline & & $M$ & $S D$ & $M$ & $S D$ & $M$ & $S D$ \\
\hline Satisfaction & $1-9$ & 7.54 & 1.43 & 6.62 & 1.7 & 7.47 & 1.47 \\
\hline \multicolumn{8}{|l|}{ Affective Response Measure } \\
\hline Anticipated Jealousy & $1-7$ & 2.5 & 1.35 & 2.17 & 1.35 & 5.46 & 1.34 \\
\hline Anticipated Compersion & $1-7$ & 5.19 & 1.35 & 5.31 & 1.42 & 1.83 & 1.23 \\
\hline Real-life Experience Index & $0-1$ & 0.56 & 0.34 & 0.60 & 0.35 & 0.13 & 0.23 \\
\hline
\end{tabular}


Table 3.

Anticipated Negative Affect (Jealousy)

\begin{tabular}{|c|c|c|c|c|c|c|c|}
\hline & & \multicolumn{2}{|c|}{$\begin{array}{l}\text { Monogamous } \\
\text { and Primary } \\
\text { Relationships }\end{array}$} & & \multicolumn{2}{|c|}{$\begin{array}{c}\text { Monogamous and } \\
\text { Secondary } \\
\text { Relationships }\end{array}$} & \\
\hline & & $B$ & $S E$ & & $B$ & $S E$ & \\
\hline$B$ & Intercept & -0.66 & 0.03 & $* * *$ & -0.98 & 0.04 & $* * *$ \\
\hline$x 1$ & Relationship Type $\dagger$ & 2.28 & 0.09 & $* * *$ & 2.55 & 0.09 & $* * *$ \\
\hline$x 2$ & $\begin{array}{l}\text { Relationship } \\
\text { Experience }\end{array}$ & -1.15 & 0.09 & $* * *$ & -1.25 & 0.11 & $* * *$ \\
\hline$x 1 * x 2$ & Interaction & -0.59 & 0.24 & $*$ & -0.49 & 0.25 & $*$ \\
\hline
\end{tabular}

Note: $†$ Relationship Type was dummy-coded as "Monogamous" (1)/"Polyamorous" (0). *p < $.05, * * p<.01, * * * p<.001$. 
Table 4.

Anticipated Positive Affect (Compersion)

\begin{tabular}{|c|c|c|c|c|c|c|c|}
\hline & & \multicolumn{2}{|c|}{$\begin{array}{l}\text { Monogamous and } \\
\text { Primary } \\
\text { Relationships }\end{array}$} & & \multicolumn{2}{|c|}{$\begin{array}{l}\text { Monogamous and } \\
\text { Secondary } \\
\text { Relationships }\end{array}$} & \\
\hline & & $B$ & $S E$ & & $B$ & $S E$ & \\
\hline$b$ & Intercept & -1.80 & 0.08 & $* * *$ & -1.58 & 0.08 & $* * *$ \\
\hline$x 1$ & $\begin{array}{l}\text { Relationship } \\
\text { Type } \dagger\end{array}$ & 2.57 & 0.09 & $* * *$ & 2.62 & 0.09 & $* * *$ \\
\hline$x 2$ & $\begin{array}{l}\text { Relationship } \\
\text { Experience }\end{array}$ & 2.14 & 0.22 & $* * *$ & 2.14 & 0.22 & $* * *$ \\
\hline$x 1 * x 2$ & Interaction & -0.96 & 0.24 & $* * *$ & -0.81 & 0.25 & $* *$ \\
\hline
\end{tabular}

Note: $\uparrow$ Relationship Type was dummy-coded as "Polyamorous" (1)/"Monogamous" (0). *p < $.05, * * p<.01, * * * p<.001$. 
Table 5.

Role of Positive Affect, Negative Affect, and Emotional Ambivalence on Relationship Satisfaction

\begin{tabular}{|c|c|c|c|c|c|c|}
\hline \multirow[b]{3}{*}{ Intercept } & \multicolumn{2}{|c|}{$\begin{array}{c}\text { Monogamous and } \\
\text { Primary Relationships }\end{array}$} & \multicolumn{4}{|c|}{$\begin{array}{l}\text { Monogamous and } \\
\text { Secondary } \\
\text { Relationships }\end{array}$} \\
\hline & $B$ & $S E$ & & $B$ & $S E$ & \\
\hline & 7.22 & 0.06 & & 6.24 & 0.09 & \\
\hline Gender Identity $\dagger$ & 0.14 & 0.06 & $*$ & 0.07 & 0.08 & \\
\hline Relationship Type & -0.09 & 0.14 & & 0.90 & 0.15 & $* * *$ \\
\hline Negative Affect ${ }^{0}$ & -0.03 & 0.05 & & 0.06 & 0.07 & \\
\hline Positive Affect ${ }^{0}$ & 0.17 & 0.05 & $*$ & 0.23 & 0.07 & $* *$ \\
\hline \multicolumn{7}{|l|}{ Interactions } \\
\hline $\begin{array}{l}\text { Positive Affect x } \\
\text { Gender }\end{array}$ & 0.05 & 0.06 & & 0.00 & 0.08 & \\
\hline $\begin{array}{l}\text { Negative Affect x } \\
\text { Gender }\end{array}$ & 0.04 & 0.06 & & 0.04 & 0.08 & \\
\hline $\begin{array}{l}\text { Negative Affect x } \\
\text { Relationship Type }\end{array}$ & 0.14 & 0.08 & & 0.00 & 0.10 & \\
\hline $\begin{array}{l}\text { Positive Affect x } \\
\text { Relationship Type }\end{array}$ & -0.11 & 0.08 & & -0.14 & 0.09 & \\
\hline $\begin{array}{l}\text { Positive Affect x } \\
\text { Negative Affect }\end{array}$ & -0.03 & 0.02 & & -0.05 & 0.02 & $*$ \\
\hline
\end{tabular}

Note: $\uparrow$ Gender was dummy-coded as "Female" (1)/"Male" (0); + Relationship Type was dummy-coded as "Monogamous" (1)/"Polyamorous" (0). ${ }^{0}$ Positive and Negative Affect measures were mean centered. $* p<.05, * * p<.01, * * * p<.001$. 